When ethanolic extracts of the roots were chromatographed on paper in the petroleum ether-formamide system and on talc in the $n$-hexane-ethyl acetate (3:1) and petroleum ether-ether (3:1) systems [3], more than 15 substances of coumarin nature were isolated from these two species.

The isolation and separation of the coumarins was carried out by a known procedure [4]. The roots of $\mathrm{H}$. willelmsii yielded five substances in the pure crystalline state which were identified as osthole $\left(\mathrm{C}_{15} \mathrm{H}_{16} \mathrm{O}_{4}, \mathrm{mp}^{83-84^{\circ}} \overline{\mathrm{C}), \mathrm{pim}-}\right.$

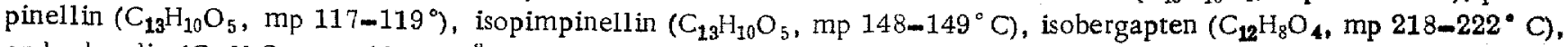
and sphondin $\left(\mathrm{C}_{12} \mathrm{H}_{8} \mathrm{O}_{4}, \mathrm{mp} 190-192^{\circ} \mathrm{C}\right)$. sphondin.

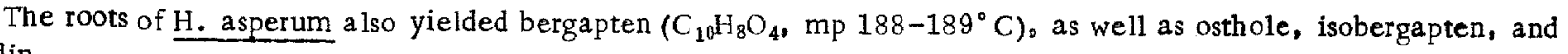

Umbelliferone, scopoletin, angelicin, psoralen, and imperatorin were identified in the species studied by paper chromatography in various systems. This is the first instance of the detection of both imperatorin and scopoletin in the genus Heracleum. In addition to this, the ethanolic extracts of these plants gave sucrose (yield about $5 \%$ ).

\title{
REFERENCES
}

1. I. F. Satsyperova, in: Terpenoids and Coumarins [in Russian], Moscow and Leningrad, 1965.

2. I. P. Mandenova, Caucasian Species of the Genus Heracluem [in Russian], Tiflis, 1950.

3. N. F. Komissarenko et a1., Biokhim., 26, No. 6, 980, 1961.

4. D. G. Kolesnikov, N. F. Komissarenko, and V. T. Chernobai, Med. prom. SSSR, No. 6, 32, 1961.

16 June 1967

Kutateladze Institute of Pharmacochemistry, AS Georgian SSR Kharkov Chemical and Pharmaceutical Scientific-Research Institute

UDC $577.15 / 17.58289$

\section{A STUDY OF CNIDIMIN AND ITS IDENTIFICATION WITH LIBANOTIN}

\author{
G. K. Nikonov
}

Khimiya Prirodnykh Soedinenii, Vol. 4, No. 1, p. 48, 1968

We have previously reported the isolation from the fruit of Cnidium monnieri (L.) Cuss. of a coumarin $\mathrm{C}_{18} \mathrm{H}_{20} \mathrm{O}_{6}$, which we called cnidimin [1]. As further investigations have shown, cnidimin can retain several organic solvents in the form of solvates. Drying the substance by heating these leads not only to the elimination of the solvent of crystallization from the solvate but also to its degradation, accompanied by the splitting off of a volatile acids.

By crystallizing the lactone from a mixture of dioxane and petroleum ether with subsequent drying in vacuum over phosphorous pentoxide at room temperature, we obtained an acylcoumarin free from solvent of crystallization and decom-

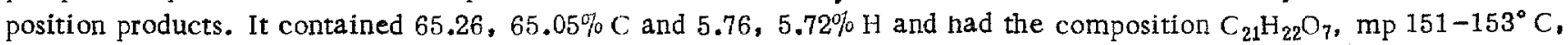
$[a]_{D}^{18}+112.1^{\circ}$ (c 0.51 : ethanol). From the features of its IR spectrum and the mixed melting point test, this substance was shown to be identical with a sample of libanotin [2] kindly provided by A. P. Prokopenko.

\section{REFERENCES}

1. G. K. Nikonov, ZhOKh, 34, No. 4, 1350, 1964.

2. A. P. Prokopenko, KhPS [Chemistry of Natural Compounds], 215, 1965. 